\title{
Ann Arbor Stage IIIS
}

National Cancer Institute

\section{Source}

National Cancer Institute. Ann Arbor Stage IIIS. NCI Thesaurus. Code C150550.

An Ann Arbor classification lymphoma stage term that refers to the involvement of lymph nodes on both sides of the diaphragm plus involvement of the spleen. 